\title{
Autosomal recessive cerebral atrophy
}

INSERM

\section{Source}

INSERM. (1999). Orphanet: an online rare disease and orphan drug data base. Autosomal recessive cerebral atrophy. ORPHA:363969

Autosomal recessive cerebral atrophy is a rare, genetic, neurodegenerative disorder characterized by ventriculomegaly and progressive, symmetrical atrophy of the cerebral cortex grey and white matter (sparing the midbrain, brainstem, cerebellum and infratentorial segments), manifesting in early infancy with acquired microcephaly, irritability, regression of developmental milestones, feeding difficulties, akathisia, exaggerated startle response, spasticity (fisted hands, stiff arms, leg scissoring), abnormal muscle tone with hypotonic trunk and hypertonic extremities, visual impairment and seizures. 